\title{
Design Analysis of a High Temperature Radiator for the Variable Specific Impulse Magnetoplasma Rocket (VASIMR)
}

\author{
Rubik B. Sheth, Eugene K. Ungar, and Joe P. Chambliss \\ NASA Johnson Space Center \\ Leonard D. Cassady \\ Ad Astra Rocket Company
}

\begin{abstract}
The Variable Specific Impulse Magnetoplasma Rocket (VASIMR), currently under development by Ad Astra Rocket Company, is a unique propulsion system that can potentially change the way space propulsion is performed. VASIMR's efficiency, when compared to that of a conventional chemical rocket, reduce propellant needed for exploration missions by a factor of 10 . Currently plans include flight tests of a $200 \mathrm{~kW}$ VASIMR system, titled VF-200, on the International Space Station. The VF-200 will consist of two $100 \mathrm{~kW}$ thruster units packaged together in one engine bus. Each thruster unit has a unique heat rejection requirement of about $27 \mathrm{~kW}$ over a firing time of 15 minutes. In order to control rocket core temperatures, peak operating temperatures of about $300^{\circ} \mathrm{C}$ are expected within the thermal control loop. Design of a high temperature radiator is a unique challenge for the vehicle design. This paper will discuss the path taken to develop a steady state and transient based radiator design. The paper will describe radiator design options for the VASIMR thermal control system for use on ISS as well as future exploration vehicles.
\end{abstract}

